\title{
Seismic Performance of Substrate for Vegetation Concrete from Large-Scale Shaking Table Test
}

\author{
Honglue Qu $\mathbb{D},,^{1,2}$ Chenxu Wang, ${ }^{1}$ Xiaole Huang, ${ }^{2,3}$ Yu Ding, ${ }^{2,3}$ and Xue Huang ${ }^{1}$ \\ ${ }^{1}$ School of Geoscience and Technology, Southwest Petroleum University, Chengdu, Sichuan 610500, China \\ ${ }^{2}$ Engineering Research Center of Eco-environment in Three Gorges Reservoir Region, Ministry of Education, \\ China Three Gorges University, Yichang, Hubei 443002, China \\ ${ }^{3}$ College of Civil Engineering and Architecture, China Three Gorges University, Yichang, Hubei 443002, China \\ Correspondence should be addressed to Honglue Qu; geoqhl@126.com
}

Received 5 November 2020; Accepted 24 November 2020; Published 9 December 2020

Academic Editor: Roberto Palma

Copyright (C) 2020 Honglue Qu et al. This is an open access article distributed under the Creative Commons Attribution License, which permits unrestricted use, distribution, and reproduction in any medium, provided the original work is properly cited.

\begin{abstract}
The substrate for vegetation concrete is a new type of plant substrate used for slope protection. While it has demonstrated good performance in slope protection and a greening effect, the sustainability of ecological restoration projects is difficult and there are significant construction risks in areas with frequent earthquakes. In this study, a new type of substrate for vegetation concrete was developed for areas with frequent earthquakes, and a shaking table test was performed to evaluate the seismic performance. The test results indicated that the proposed substrate of the vegetation concrete displayed good stability under seismic excitation at earthquake intensities of V, VI, VII, and VIII. A comparison of several different reinforcement methods under seismic conditions indicated that wavy laying of a flexible net was the best reinforcement method. Through observation of the displacement time history curve and macroscopic phenomenon, the failure process of the substrate layer was obtained and consisted of the following three stages: cracking between substrate layer and bedrock, internal cracking of the substrate layer, and vibration crushing. Ultimately, the research results have significant reference value for ecological restoration projects using substrates for vegetation concrete in areas with frequent earthquakes.
\end{abstract}

\section{Introduction}

Since the 20th century, a large number of engineering construction projects have seriously damaged the ecological environments of many regions around the world. These projects, which include the construction of roads, railways, and mining and hydropower projects, have resulted in a large number of engineering wounds in the vicinity of the construction area. In addition, these types of projects destroy the original vegetation, which causes a series of ecological and environmental problems. The natural recovery of these slopes is slow and, thus, requires a lot of time $[1,2]$. Therefore, it has become necessary to develop methods to artificially repair engineering wounds generated by construction activities.

Several European and North American countries have long studied the repair of engineering wounds in the field of ecological restoration. France first developed reinforced substrates made of continuous fibres. Japan has only more recently begun research in this area, but the research carried out has been the most in-depth. Haneda [3] proposed the use of high-order granules as binders to be added to the selfdeveloped thick substrate as the basis of the soil flock greening method of high-order granules. After that, the French substrate technology of continuous fibre reinforcement was introduced, and when combined with existing domestic technology, it resulted in the development of the substrate technology of green planting [4]. In recent years, the addition of various beneficial microbial bacteria to vegetative substrates has been considered, in order to enhance the microorganism activity of the substrate and promote the availability of nutrients for plant absorption. This led to the development of the greening method of soil fungi [5]. China introduced foreign technology for 
ecological restoration and carried out research on related applications near the end of the 20th century. Zhang et al. [6] and Luo et al. [7] developed a vegetative substrate made of a thick layer material that was based on the thick substrate developed in Japan. This design mitigated the high $\mathrm{pH}$ value of the substrate, and when the grass-water mixing design was introduced into the substrate formulation, the stability of the planting community was improved. Xu et al. [8] proposed a technique for the eco-restoration of vegetation concrete using ordinary Portland cement as a substrate binder, which resulted in significant improvement in the strength and comprehensive durability of the substrate. At the same time, a special greening additive was developed, which can effectively neutralize the alkalinity of the cement and provide nutrients for vegetation growth [9]. Li et al. [10] used a spray seeding technology of higher-order granules to repair an abandoned quarry, with the resultant vegetation coverage rate up to $95 \%$. Zhao et al. [11] carried out experimental research on the characteristics of vegetation concrete, obtained the optimum mix ratio of biochar modified vegetation concrete, and concluded that the addition of biochar particles can improve the characteristics of vegetation concrete. Among the many developed ecological restoration techniques, vegetation concrete slope protection greening technology has been widely used in practical engineering owing to the specific formula for the substrate for vegetation concrete (SVC) and seed, as well as its excellent performance in various types of hard slopes and high-steep slopes with gradients greater than $45^{\circ}$, as shown in Figure 1.

At present, research on plant growing substrates mainly focuses on the spatiotemporal variation of the substrate nutrients, comprehensive fertility surveys, water evaporation and permeability characteristics, improved fertilizer performance, etc. The majority of relevant ecological restoration projects are executed in low-altitude and low-latitude regions with good soil quality [12-14]. However, the sustainability of existing SVCs used in ecological restoration projects is not high, and there are risks of repeated construction in area with frequent earthquakes. Therefore, the seismic performance of the SVC was evaluated in this study to prepare and optimize the key materials for ecological restoration of engineering wounds in area with frequent earthquakes. In addition, a shaking table test was carried out to optimize the seismic performance and ensure the effective restoration of regional engineering wounds.

\section{Substrate Ratio Test}

Several researchers have studied the mechanism of plant root reinforcement in slopes and the biological characteristics of vegetation. Martel [15] and Roering et al. [16] showed that plant roots can anchor shallow rhizosphere soil and deep soil together to form a whole, which plays an important role in antisliding and soil enhancement. Plant roots have a significant effect on the shear resistance of soil, and appropriate roots can improve soil shear resistance. However, a difference of soil strengths has been observed within the region because the distribution of plant roots cannot be artificially controlled [17]. Therefore, a flexible fibre with excellent performance characteristic was selected, and a fibre reinforced substrate was prepared to improve the performance of the conventional substrate.

Kriker et al. [18] and Ozerkan et al. [19] have studied the mechanical properties of palm fibres. The experimental results indicated that a sufficient quantity of fibres can enhance the tensile properties of cement mortar and concrete. Thus, palm fibre was selected for the test owing to its wide use and low cost. In addition, a static nonconsolidation and nondrainage triaxial test was carried out to test the shear strength of the SVC. The test instrument used was a TSZ302.0 strain-controlled triaxial apparatus, as shown in Figure 2.

In order to ensure that the SVC met the required plant growth conditions and engineering durability, multiple ratio optimization tests were carried out according to the application conditions in practical engineering $[20,21]$. In the test, the substrate was arranged in a mass ratio (soil: cement: organic matter: greening additive $=100: 8: 6: 4)$, the dry density was $1.35 \mathrm{~g} / \mathrm{cm}^{3}$, and the initial moisture content was $20 \%$. The tests used five different mass ratios of palm fibre that included $0 \%, 0.2 \%, 0.4 \%, 0.6 \%$, and $0.8 \%$. The static nonconsolidation and nondrainage triaxial tests were conducted on the substrate under the conditions of a confining pressure of $30 \mathrm{kPa}$ and a dry/wet cycle amplitude of 10 cycles that was $15 \%$ and $25 \%$, respectively. The mechanical parameters of the substrate obtained in the test are shown in Figure 3 .

It can be seen from Figure 3 that the shear strength of the substrate over 10 dry/wet cycles was the highest when the amount of palm fibre was $0.4 \%$. The initial moisture content of the reinforced substrate was $20 \%$, and the cement content was controlled at approximately $8 \%$ [14]. It should be noted that the water content of the other materials should be considered when the ratio was matched. The substrate ratios of the test are shown in Table 1.

Local laterite was selected as the planting soil for the test. The soil and sawdust were air-dried and passed through a $2 \mathrm{~mm}$ mesh screen. The cement used was P.C32.5 composite Portland cement, and the activation additive of the SVC was a patented product from the Research Center for Slope Protection and Ecological Restoration of Three Gorges University.

\section{Shaking Table Model Test Design}

3.1. Test Facilities. The test was carried out on a horizontal two-way shaking table at the Center of Construction Engineering Quality Inspection of Hainan University in China. The shaking table was $3 \mathrm{~m} \times 3 \mathrm{~m}$ in size and had four degrees of freedom, a maximum loading weight of $10 \mathrm{t}$, a maximum overturning moment of $30 \mathrm{t} \mathrm{m}$, a maximum torsional force of $10 \mathrm{t} \mathrm{m}$, a working frequency band is $0 \sim 50 \mathrm{~Hz}$, and a maximum acceleration in the $X$ (longitudinal) and $Y$ (lateral) directions of $1.1 \mathrm{~g}$ at full load. The dynamic stress-strain data acquisition system had 64 channels. The highest continuous sampling rate was $5 \mathrm{kHz} / \mathrm{channel}$, and the power supply was 220 VAC. The stress-strain voltage signals were accurately measured. In conjunction with various bridge type sensors, 


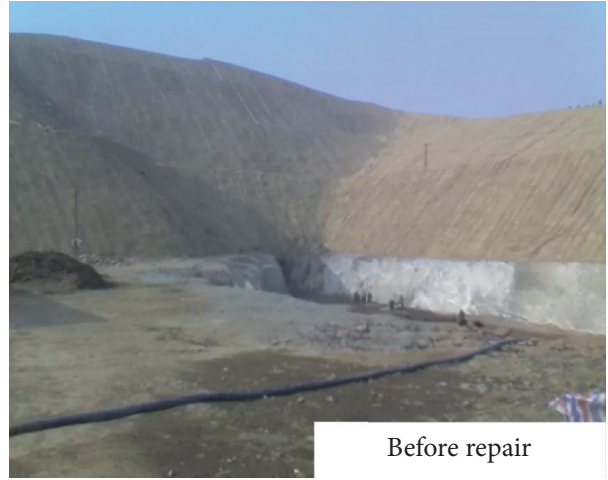

(a)

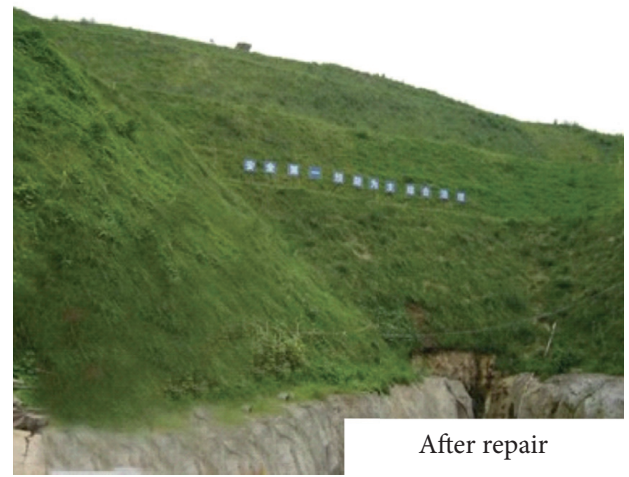

(b)

Figure 1: Ecological restoration project of excavation slope from Yanshan reservoir in Henan.

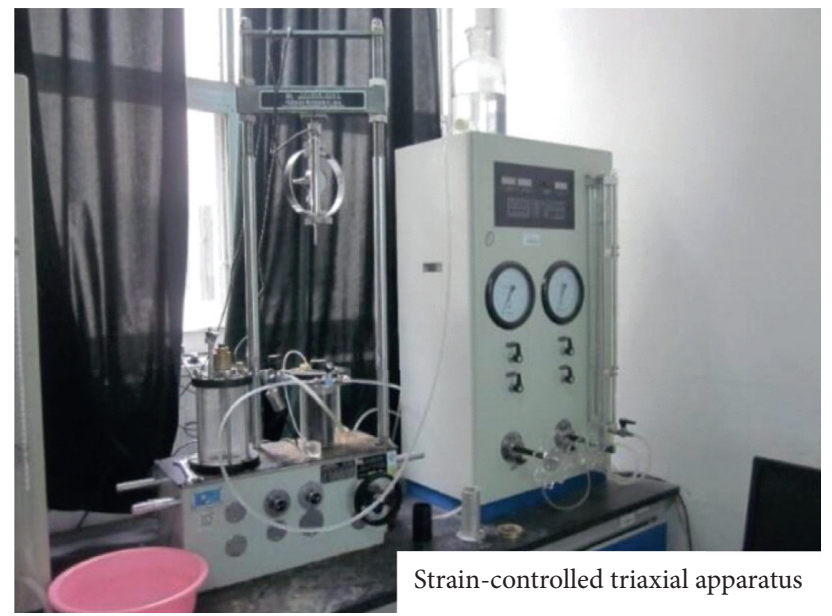

(a)

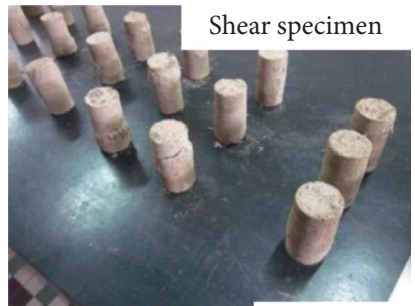

(b)

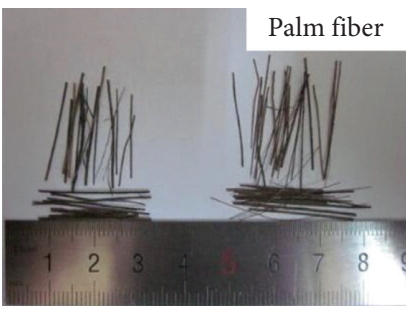

(c)

FIgURE 2: Test instrument and shear specimen.

data acquisition, signal monitoring, and online analysis were carried out simultaneously, as shown in Figure 4.

3.2. ModelDesign. Most of the shaking table tests utilized the scale test, which required a sufficient similarity relationship between the model and the prototype so as to maintain the correct geometric size and material performance of the model and prototype structure [22]. However, the selected similar materials reflected the defects encountered in the actual engineering problem. Therefore, this experimental model used a prototype test with a similarity ratio of $1: 1$. Experiments were carried out to test the bonding performance and failure of the reinforced substrate and bedrock under seismic excitation. A portion of the slope was selected for the test to reflect the vibration of the entire slope substrate.

The rigid box was used in the test with an internal size of $2 \mathrm{~m} \times 1.5 \mathrm{~m} \times 1.6 \mathrm{~m}$ (length $\times$ width $\times$ height), a set of $\mathrm{six}$ bedrock masses, two patterns of anchor roof spacing, and two kinds of reinforcement mesh. The specific size and details are shown in Figure 5 and Table 2. In order to test the seismic performance of the substrate, C30 concrete was used to construct the bedrock. The SVC bulk density was $16.8 \mathrm{kN} /$ $\mathrm{m}^{3}$, the cohesion was $99.85 \mathrm{kPa}$, and the internal friction angle was $33.59^{\circ}$. The moisture contents were designed to be 


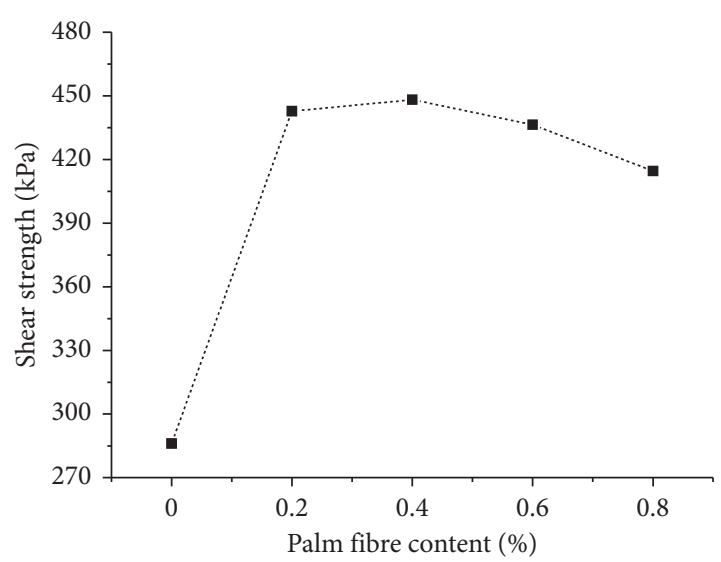

(a)

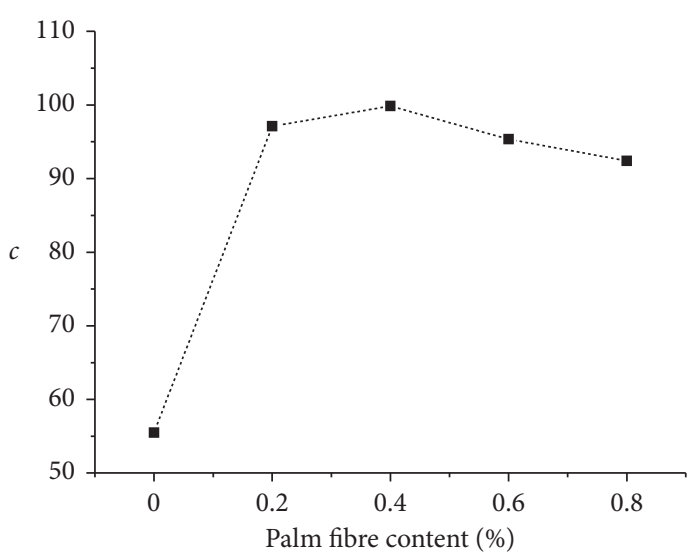

(b)

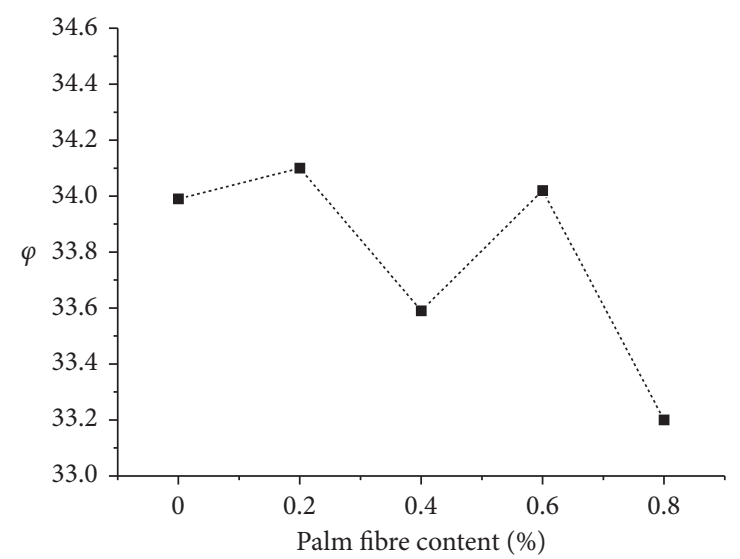

(c)

Figure 3: Mechanical parameters of substrate under different palm fibre contents. (a) Shear strength. (b) Cohesion. (c) Friction angle.

TABLE 1: The raw material ratio.

\begin{tabular}{|c|c|c|c|c|c|}
\hline Raw material & Soil & Cement & Sawdust & Activation additive & Palm fibre \\
\hline Ratio & $100 / 118$ & $8 / 118$ & $6 / 118$ & $4 / 118$ & $0.4(\%)$ \\
\hline
\end{tabular}

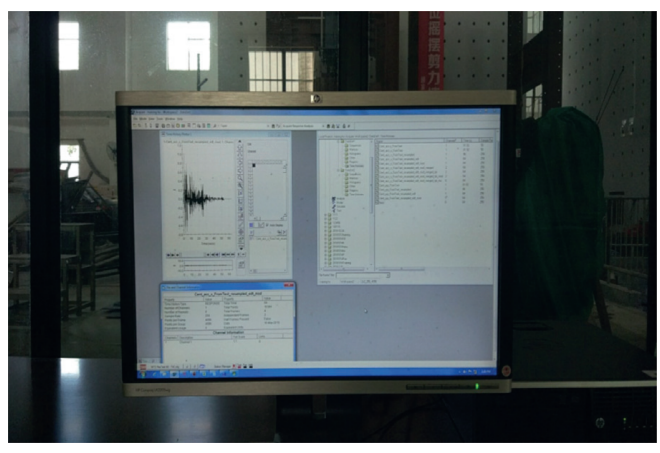

(a)

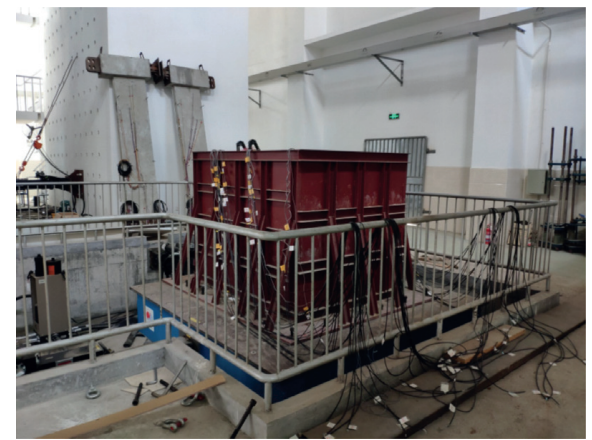

(b)

Figure 4: Data acquisition system and rigid box for the shaking table test. 


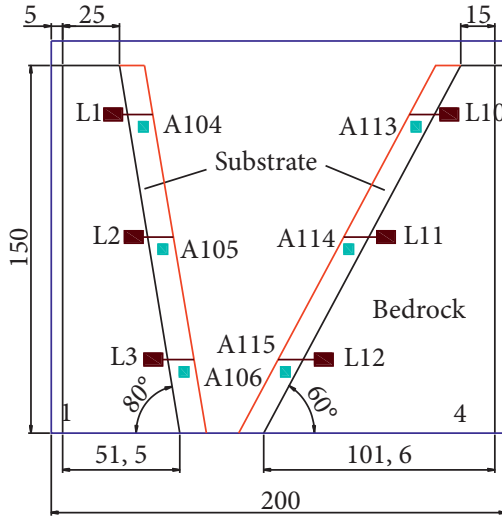

Displacement meter

- Accelerometer

(a)

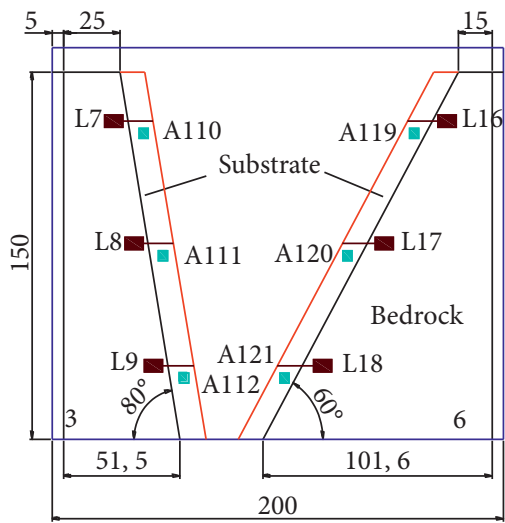

$\rightarrow$ Displacement meter

- Accelerometer

(c)

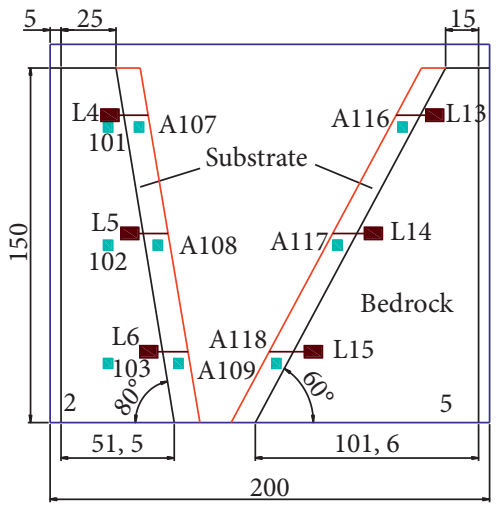

Displacement meter

- Accelerometer

(b)

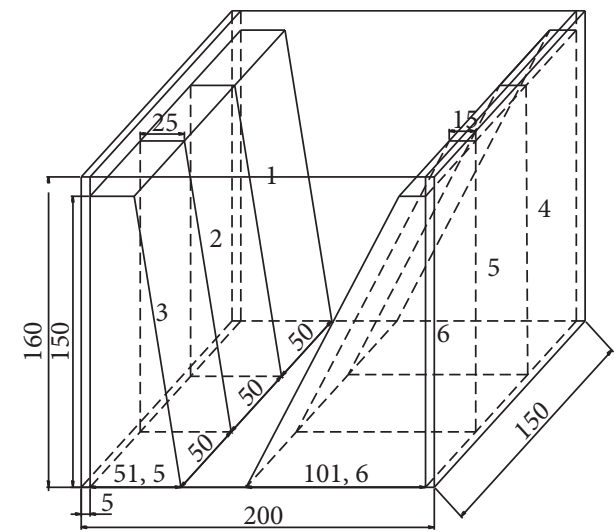

(d)

Figure 5: The test model layout. (a) 1-4 section test instrument. (b) 2-5 section test instrument. (c) 3-6 section test instrument. (d) Test model size (unit: $\mathrm{cm}$ ).

TABLe 2: The model design.

\begin{tabular}{|c|c|c|c|c|}
\hline Slope number & Slope $\left({ }^{\circ}\right)$ & Anchor spacing $(\mathrm{m})$ & Moisture content (\%) & Laying form \\
\hline 1 & 80 & $1 \times 0.5$ & 20 & A layer of flexible net wavy laying \\
\hline 2 & 80 & $1 \times 0.5$ & 20 & A layer of flexible net laying \\
\hline 3 & 80 & $1 \times 0.5$ & 20 & A layer of barbed wire flat laying \\
\hline 4 & 60 & $0.5 \times 0.5$ & 20 & A layer of flexible net wavy laying \\
\hline 5 & 60 & $1 \times 0.5$ & 25 & A layer of flexible net wavy laying \\
\hline 6 & 60 & $1 \times 0.5$ & 20 & A layer of flexible net wavy laying \\
\hline
\end{tabular}

$20 \%$ and $25 \%$, respectively. A high-strength polystyrene plastic foam board having $50 \mathrm{~mm}$ thickness was placed on the side of the shaking table in the $X$ direction of the model box to reduce the reflection of the seismic waves.

3.3. Experimental Model Construction. Concrete bedrock was placed around the outside of the model and cured for seven days to a certain strength. It was then hoisted into the rigid box using a traveling crane. Next, a reinforced net was laid for each slope body, with the substrate laid over that. The mesh size of the reinforced net was $6 \mathrm{~cm} \times 6 \mathrm{~cm}$, and the laying methods used included wavy laying and flat laying, as shown in Figure 6. The test substrate was prepared and laid by hand, and the substrate was cured for seven days, as shown in Figure 7.

3.4. Test Instrumentation. In this model, the displacement sensors and accelerometers were arranged in the layout shown in Figure 5.

3.4.1. Displacement Sensor. The test used pulling wire displacement sensors, which were arranged in the upper, middle, and lower portions of the bedrock. The displacement sensor output voltage signal was $0-10 \mathrm{~V}$, the measuring 


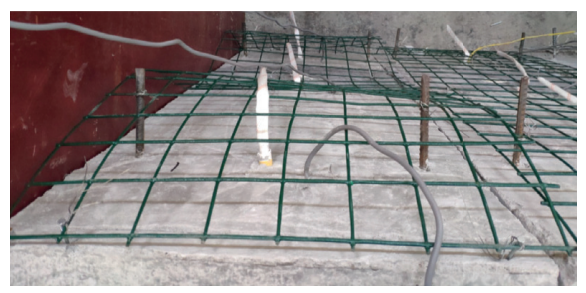

(a)

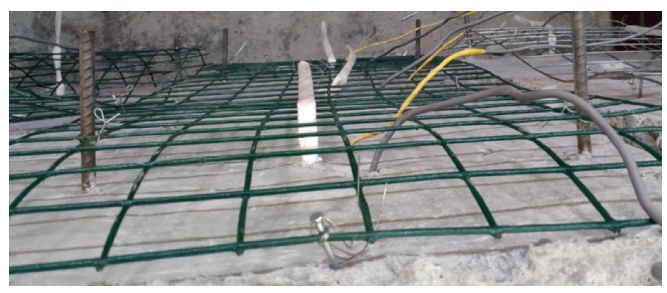

(b)

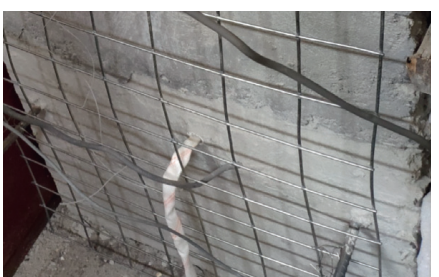

(c)

FIGURE 6: The reinforced net laying. (a) Flexible net wavy laying reinforcement. (b) Flexible net flat laying reinforcement. (c) Barbed wire flat laying reinforcement.

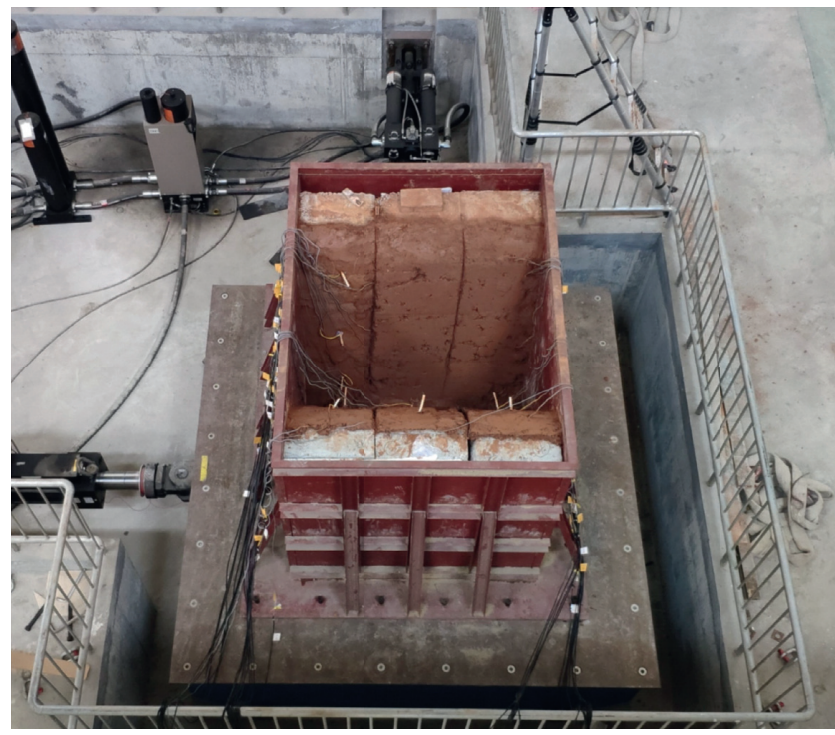

(a)
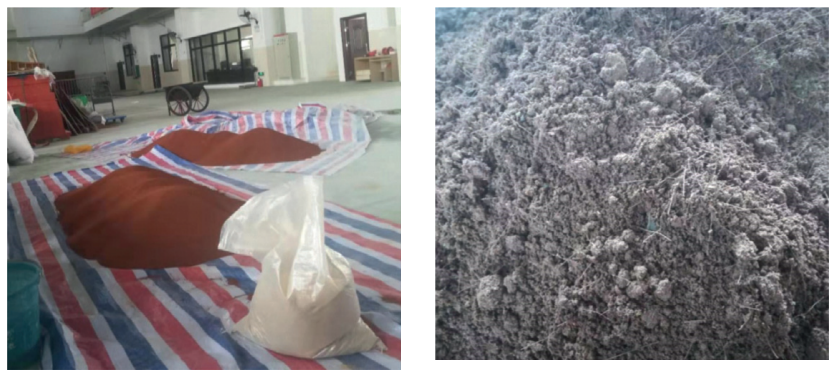

(c)

FIgURE 7: The substrate laying.

stroke was $0-500 \mathrm{~mm}$, the working temperature was $-45^{\circ} \mathrm{C}-+125^{\circ} \mathrm{C}$, and the outlet port pulling force was approximately $4 \mathrm{~N}$. The steel wire was wrapped with a plastic hose to prevent pressed pleat and wear. The channel was reserved when laying the substrate. After laying, the end of the wire displacement meter was fixed on the surface of the substrate layer, and the relative displacement between the substrate layer and the bedrock was measured. The pulling wire displacement sensor was installed as shown in Figure 8.

3.4.2. Accelerometer. A piezoresistive accelerometer was used in this test, and the acceleration sensors were arranged on the shaking table mesa, the bedrock, and the substrate layer. The range of the sensor was $\pm 50 \mathrm{~m} \mathrm{~s}^{-2}$, the frequency range was $0-250 \mathrm{~Hz} \pm 5 \%$, the resonant frequency was $>0.8 \mathrm{kHz}$, the excitation voltage was $8-16 \mathrm{~V}$, and the working temperature was $-20-80^{\circ} \mathrm{C}$. The accelerometer was placed in a protective shell and fixed with glass glue to seal the wire hole. The outer part of the protective case was wrapped with waterproof tape to ensure that the protective shell and accelerometer were basically the same weight as an equal volume of bedrock and substrate. This setup ultimately

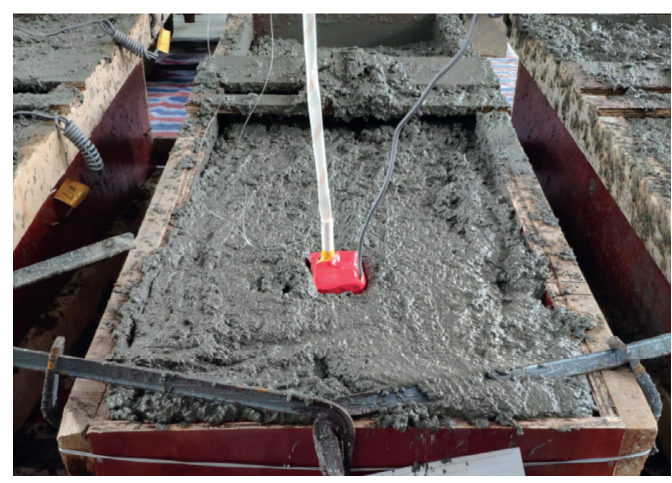

FIgURE 8: Installation of displacement sensors.

achieved the coordinated movement of the accelerometer and surrounding rock mass, as shown in Figure 9.

3.5. Loading Scheme. The El Centro wave was selected as the load in this test. The test seismic wave was not compressed, and the loading time was $40 \mathrm{~s}$. The peak ground acceleration (PGA) was input from the $X$ direction and the $Y$ direction, 


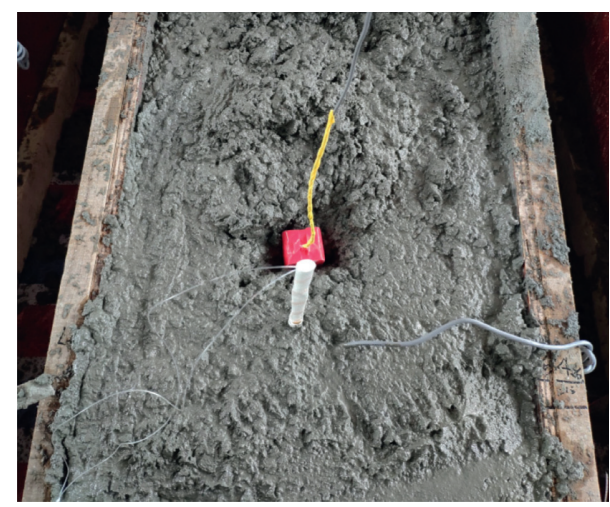

Figure 9: Installation of acceleration sensors.

and the acceleration time history of the PGA was $0.025 \mathrm{~g} \cdot \mathrm{XY}$,

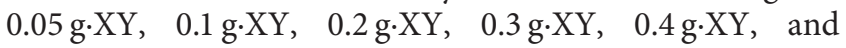
$0.5 \mathrm{~g} \cdot \mathrm{XY}$, respectively. $0.025 \mathrm{~g} \cdot \mathrm{XY}$ represented the peak input value of $0.025 \mathrm{~g}$, which was the horizontal bidirectional excitation. Prior to each shaking test, a microseismic test with a Gaussian stationary white noise excitation with a PGA of $0.02 \mathrm{~g}$ was performed with a loading time of $35 \mathrm{~s}$, and the dynamic characteristics of the model were observed. The acceleration time history curve of the test loading is shown in Figure 10.

\section{Experimental Results}

4.1. Acceleration. The acceleration time history obtained from shaking table test was analyzed. The Fourier spectrum of the acceleration response at various measuring points under ground motion with a PGA of $0.2 \mathrm{~g}$ is shown in Figure 11. The Fourier spectrum of the acceleration response at measuring point A104 with various PGAs is shown in Figure 12.

From Figures 11 and 12, it can be seen that the characteristic frequencies of the acceleration response at different locations were less affected by the PGA and location of the measuring point. Under different PGA loading conditions, as the PGA gradually increased, the first-order mode shape tended to be unimodal, while the second-order mode tended to be insignificant, and the amplitude of the high-frequency portion decreased. This indicated that the nonlinear characteristics of the model were gradually enhanced, and absorption of the ground motion energy by the bedrock and substrate layer simultaneously increased. The characteristic frequency of the recorded acceleration response was nearly almost constant, as shown in Figure 12.

The variation in the magnification factor at the acceleration point of various slope substrate layers under the El Centro seismic wave is shown in Figure 13.

From Figure 13, it can be seen that the amplification factor of the PGA generally decreased with an increase in the acceleration amplitude of the seismic wave. In addition, the change in individual monitoring points was not significant. This may be due to a significantly enhanced filtering effect and increased damping ratio and substrate shear strain caused by the increase of seismic load. A comparison of the acceleration responses of different slopes indicated that the amplification coefficients of the PGA demonstrated an elevation effect and surface effect under the same seismic load.

4.2. Displacement. The measured displacement time history of measuring point L4 under the seismic excitation of various conditions is shown in Figure 14. The "+" direction of the data indicated that the substrate layer was deformed away from the slope bedrock. When the PGA was increased to $0.3 \mathrm{~g}$, no obvious displacement was observed. However, when the PGA was increased to $0.5 \mathrm{~g}$, permanent deformation occurred at L4 that was primarily controlled by the front peak of the El Centro wave, and the deformation was completed within its action time.

The deformation displacement of the slope substrate layer was obtained based on the measured displacement response time history. The displacement of the measured substrate layer under various working conditions is shown in Figures 15 and 16. It can be seen that the displacement increased continuously with the increase in PGA (the pullwire end of the pulling wire displacement sensor shrunk due to the looseness of the substrate layer, which resulted in a negative displacement). Compared with the displacement of the $80^{\circ}$ slope substrate layer at different heights, the displacement of the barbed wire flat laying reinforcement was larger than the flexible net flat laying reinforcement. The displacement of the flexible net wavy laying reinforcement was the smallest, which indicated that the flexible net wavy laying reinforcement was the optimal net setting mode. Compared with the displacement of the $60^{\circ}$ slope substrate layer, the displacement of measuring point L16 was $0.66 \mathrm{~mm}$ when the PGA was $0.5 \mathrm{~g}$. The displacement of other measuring points was not more than $0.05 \mathrm{~mm}$. That is, there was essentially no displacement, as shown in Figure 16. It was obvious that the displacement of the $80^{\circ}$ slope substrate layer under seismic excitation was greater than $60^{\circ}$ slope.

The displacement between the substrate layer and bedrock was analyzed. For the $80^{\circ}$ slope, the displacement between the substrate and bedrock was nearly zero when the PGA was increased from $0.025 \mathrm{~g}$ to $0.3 \mathrm{~g}$. The displacement between the substrate and bedrock was small when the PGA was increased to $0.4 \mathrm{~g}$, and the displacement between the substrate and bedrock changed significantly when the PGA was increased to $0.5 \mathrm{~g}$. The displacements at measuring points L7 and L4 were $0.685 \mathrm{~mm}$ and $0.32 \mathrm{~mm}$, respectively. In this situation, the substrate was indicated to be damaged. For the $60^{\circ}$ slope, the displacement between the substrate layer and bedrock was nearly zero when the PGA was increased from $0.025 \mathrm{~g}$ to $0.4 \mathrm{~g}$, and the maximum displacement was less than $0.05 \mathrm{~mm}$. The displacement between the substrate and bedrock at the top of the slope was small when the PGA was increased to $0.5 \mathrm{~g}$ and indicated that the substrate layer was not damaged.

Based on an analysis of the displacement and acceleration time histories, it was concluded that the SVC had good stability under seismic excitations with seismic intensities of V, VI, VII, and VIII (which corresponded to PGAs of $0.025 \mathrm{~g}, 0.05 \mathrm{~g}, 0.1 \mathrm{~g}$, and $0.2 \mathrm{~g}$ ). When the seismic intensity 


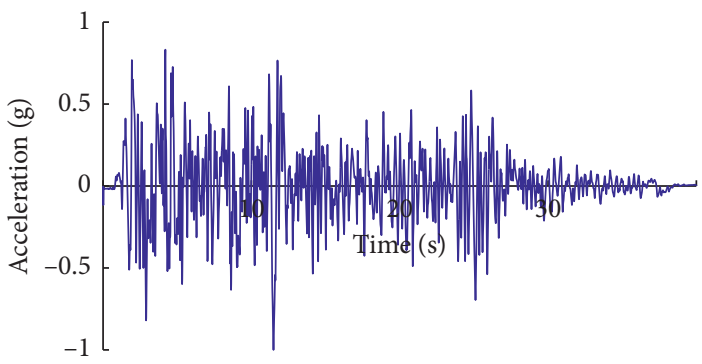

(a)

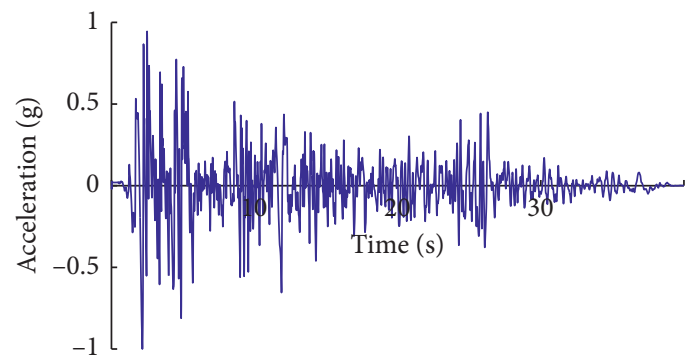

(b)

Figure 10: Acceleration time history curve of El Centro seismic wave. (a) $X$ direction. (b) $Y$ direction.

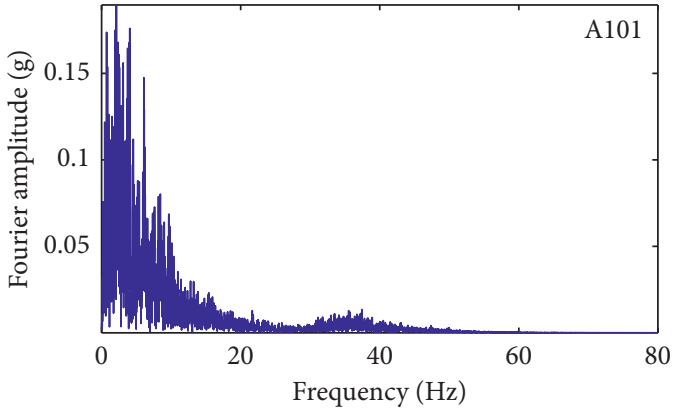

(a)

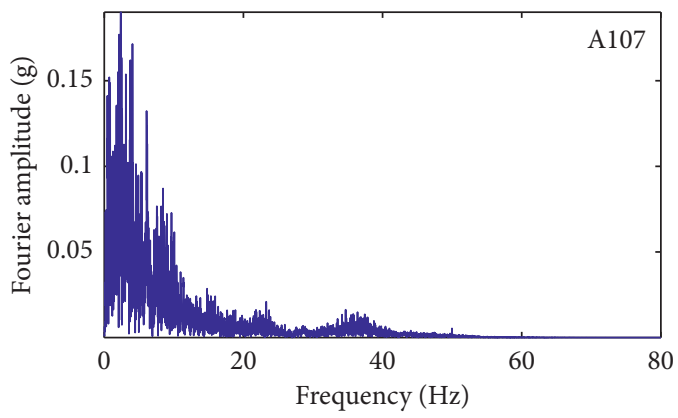

(c)

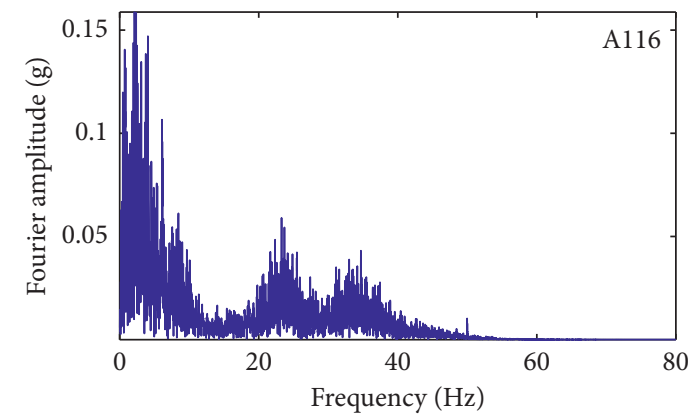

(e)

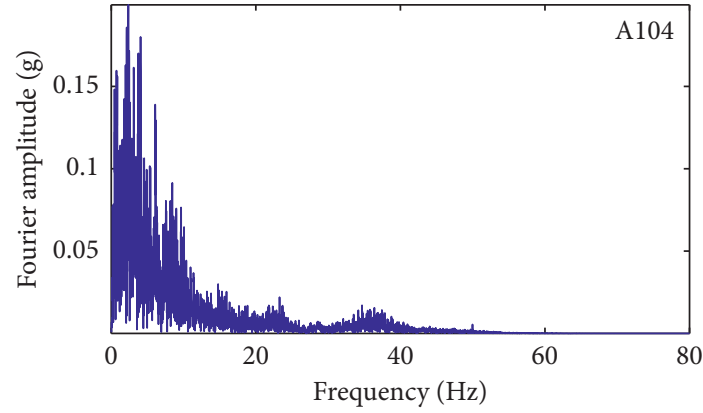

(b)

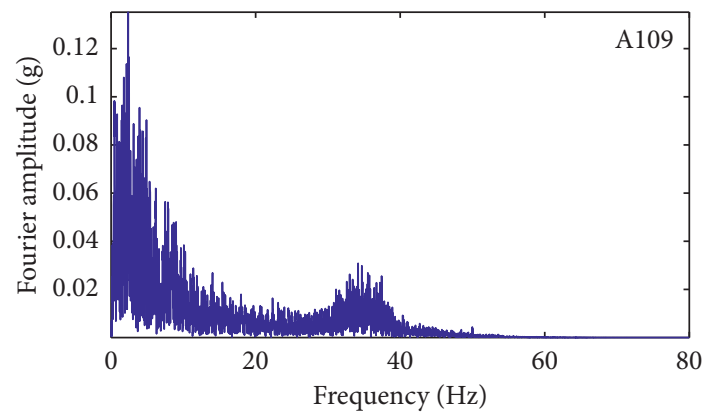

(d)

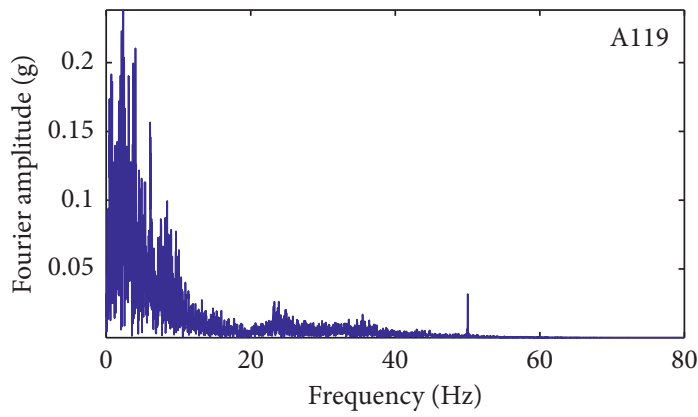

(f)

FIGURE 11: Fourier spectrum of accelerations at different measuring point under PGA of 0.2 g. (a) A101. (b) A104. (c) A107. (d) A109. (e) A116. (f) A119. 


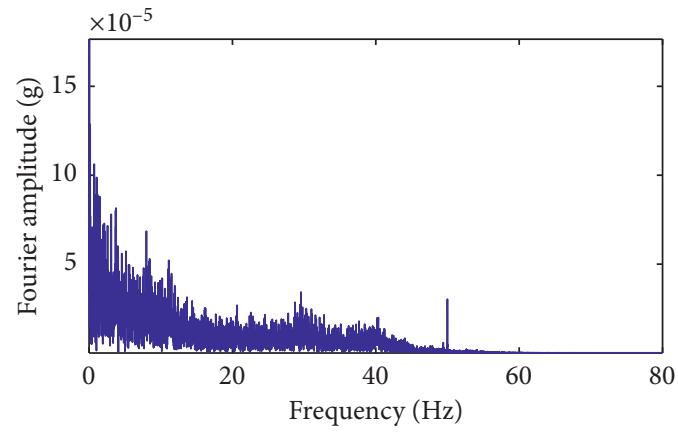

(a)

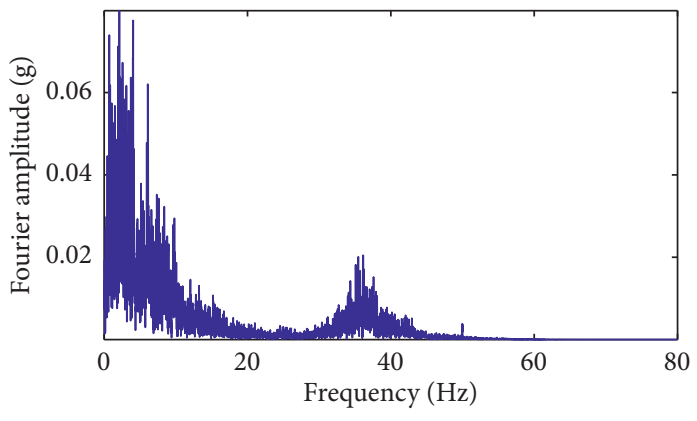

(c)

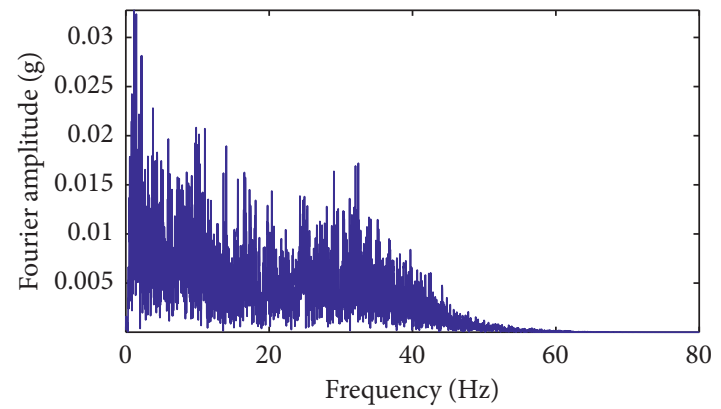

(e)

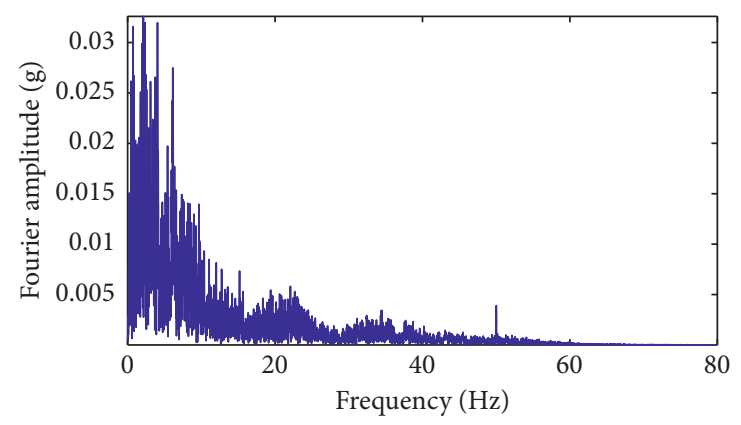

(b)

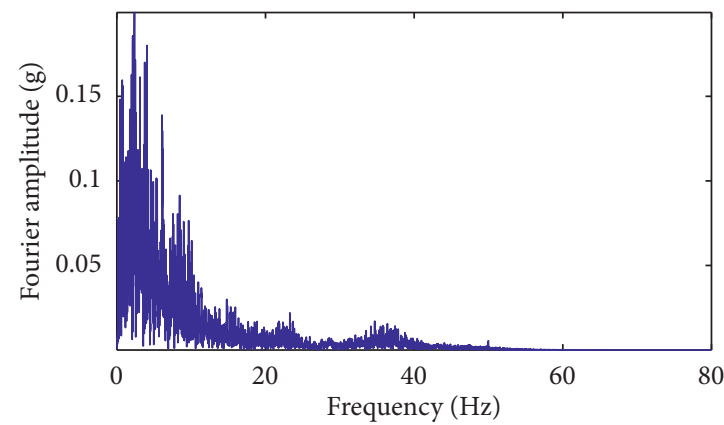

(d)

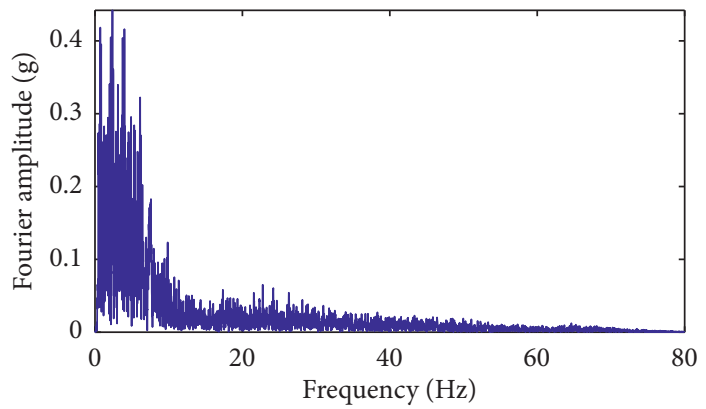

(f)

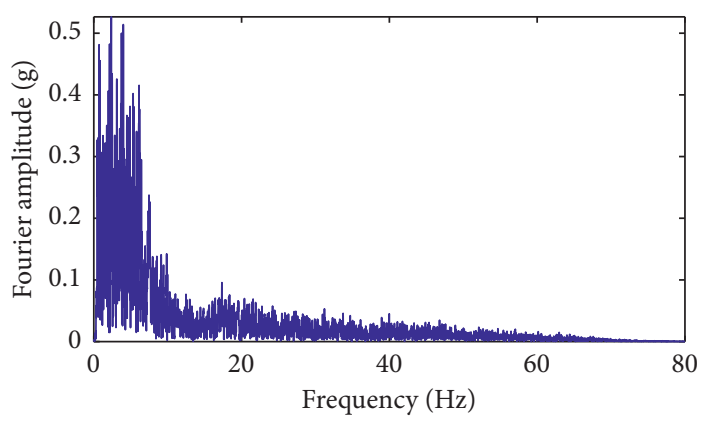

(g)

FIgURE 12: Fourier spectrum of accelerations at measuring point A104 under different PGAs. (a) $0.025 \mathrm{~g} \cdot \mathrm{XY}$. (b) $0.05 \mathrm{~g} \cdot \mathrm{XY}$. (c) $0.1 \mathrm{~g} \cdot \mathrm{XY}$. (d) $0.2 \mathrm{~g} \cdot \mathrm{XY}$. (e) $0.3 \mathrm{~g} \cdot \mathrm{XY}$. (f) $0.4 \mathrm{~g} \cdot \mathrm{XY}$. (g) $0.5 \mathrm{~g} \cdot \mathrm{XY}$. 


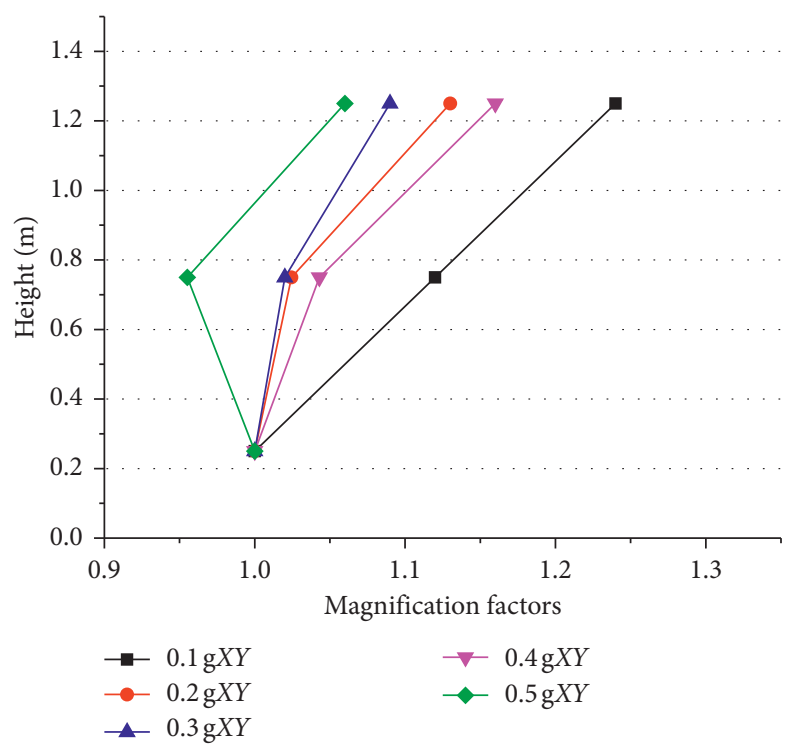

(a)

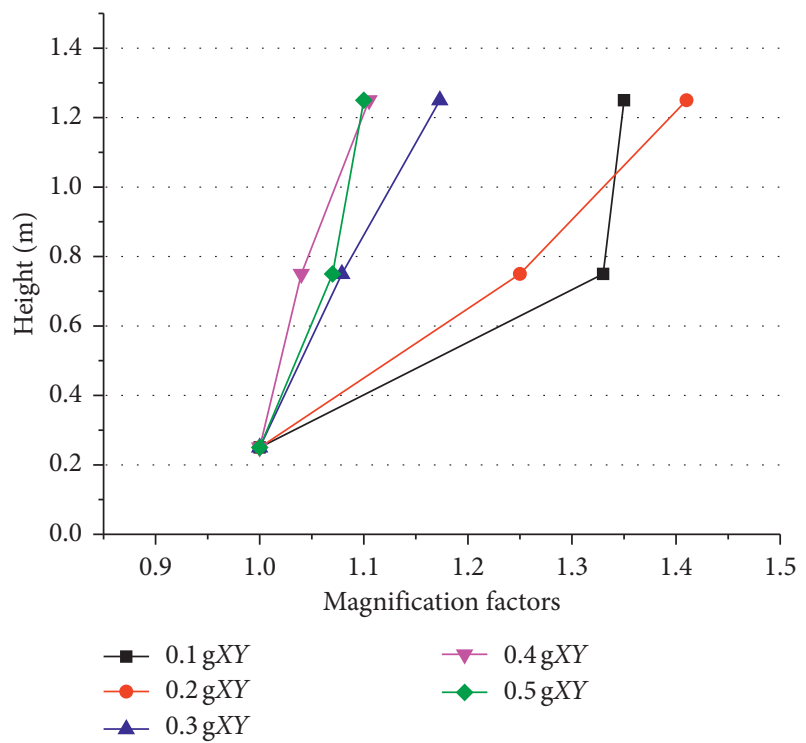

(c)

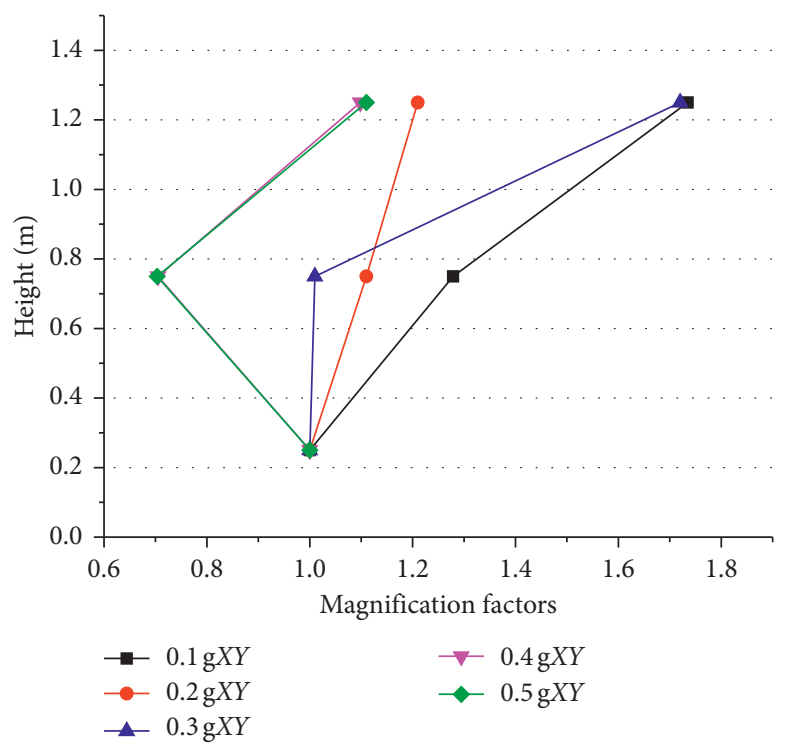

(b)

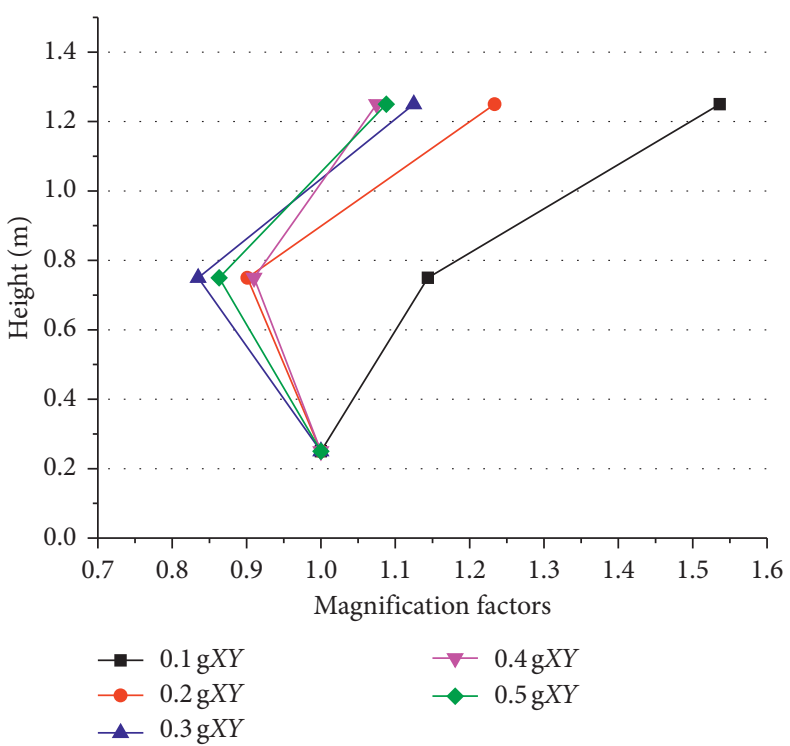

(d)

FIGURE 13: Acceleration magnification factors under the action of El Centro seismic wave. (a) Slope 1: flexible net wavy laying reinforcement. (b) Slope 2: flexible net flat laying reinforcement. (c) Slope 3: barbed wire flat laying reinforcement. (d) Slope 6: flexible net wavy laying reinforcement.

reached IX (i.e., the PGA increased from $0.3 \mathrm{~g}$ to $0.5 \mathrm{~g}$ ), the displacement between the substrate layer and bedrock body gradually increased, and the stability of the base substrate layer gradually decreased until it was destroyed.

\section{Substrate Failure Development Process and Instability Mode}

5.1. Substrate Failure Development Process. The crack propagation and instability failure of the SVC observed in the test under many earthquakes are shown in Figure 17. According to the test phenomenon, the instability failure process of the SVC under seismic action was divided into three stages.
(1) Stage 1: cracking stage between the substrate layer and bedrock. As shown in Figure 17(a), the slope has a displacement tendency of left and right swing under seismic action. Due to the existence of the surface condition of the substrate layer, cracks between the substrate layer and bedrock gradually appeared with increases in the PGA. The cracking phenomenon of the substrate layer primarily occurred in the upper part of the slope owing to the relatively large seismic force in that area. Cracking in the thickness direction of the substrate layer and bedrock can be clearly observed at the top of the slope, with a crack width of about 2-4 $\mathrm{mm}$. 


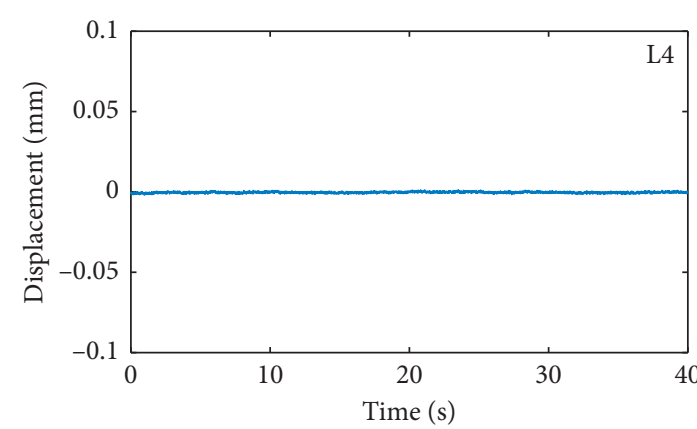

(a)

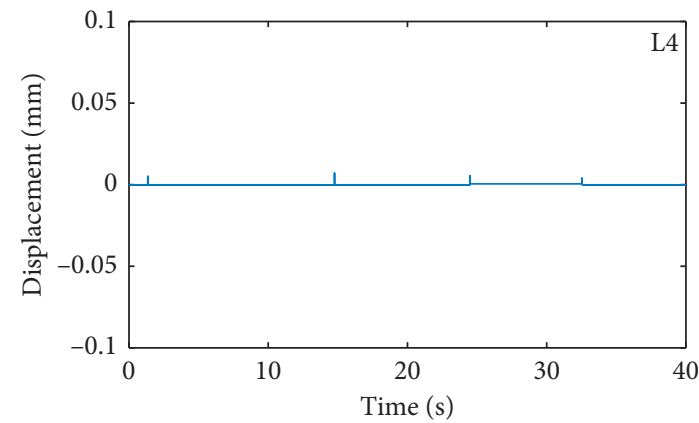

(c)

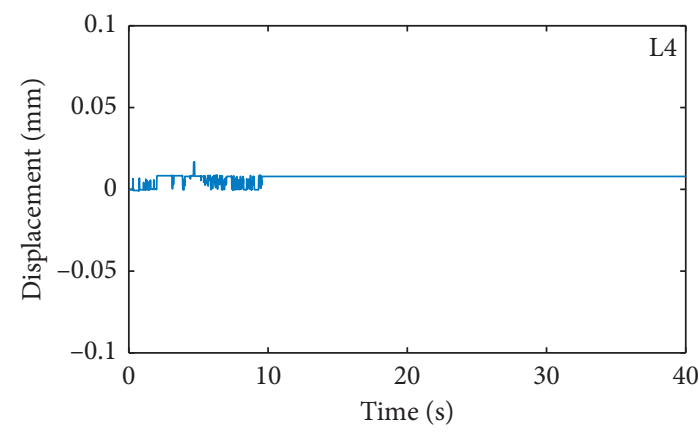

(e)

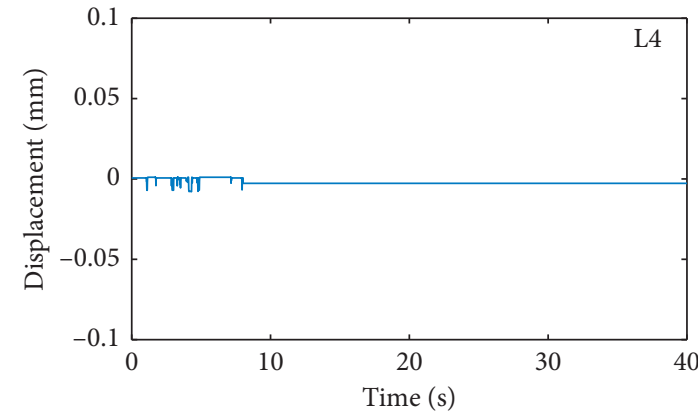

(b)

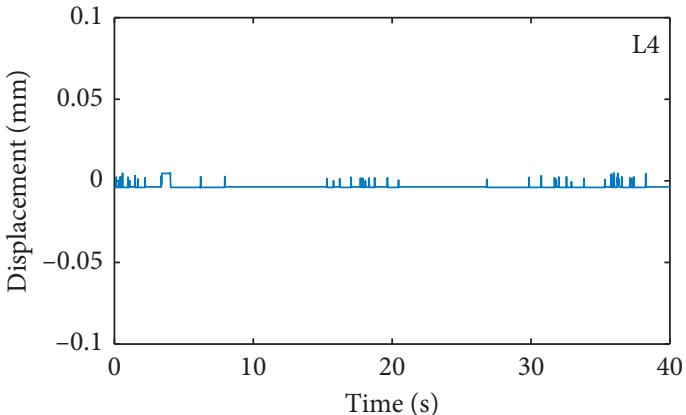

(d)

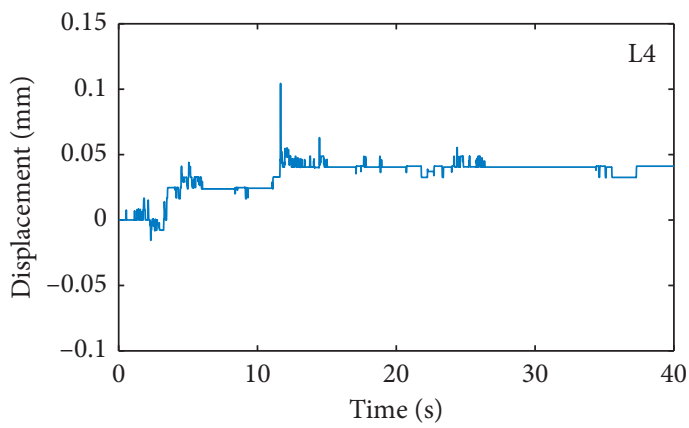

(f)

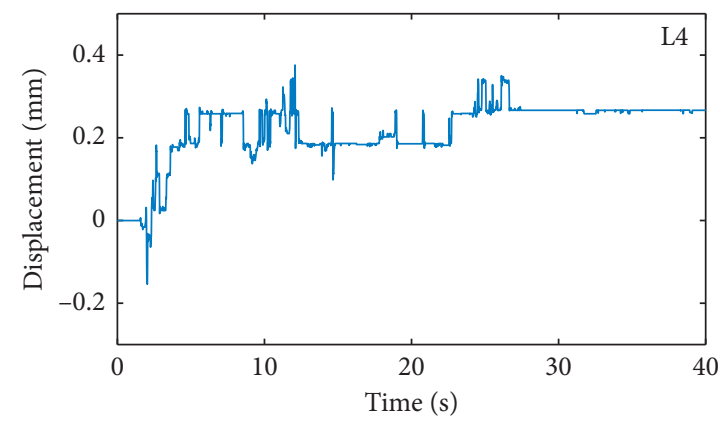

(g)

FIGURE 14: Time history of displacement response of measuring point L4 action by El Centro seismic wave. (a) $0.025 \mathrm{~g} \cdot \mathrm{XY}$. (b) $0.05 \mathrm{~g} \cdot \mathrm{XY}$. (c) $0.1 \mathrm{~g} \cdot \mathrm{XY}$. (d) $0.2 \mathrm{~g} \cdot \mathrm{XY}$. (e) $0.3 \mathrm{~g} \cdot \mathrm{XY}$. (f) $0.4 \mathrm{~g} \cdot \mathrm{XY}$. (g) $0.5 \mathrm{~g} \cdot \mathrm{XY}$. 


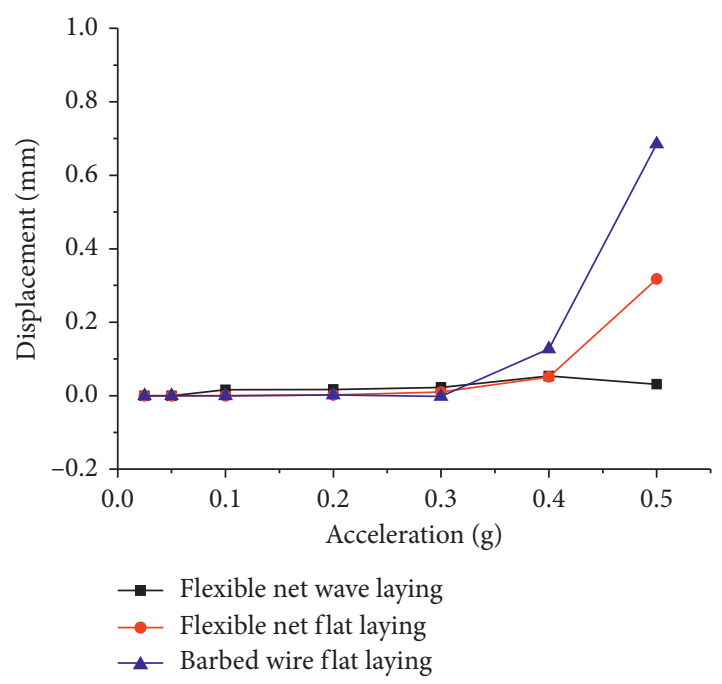

(a)

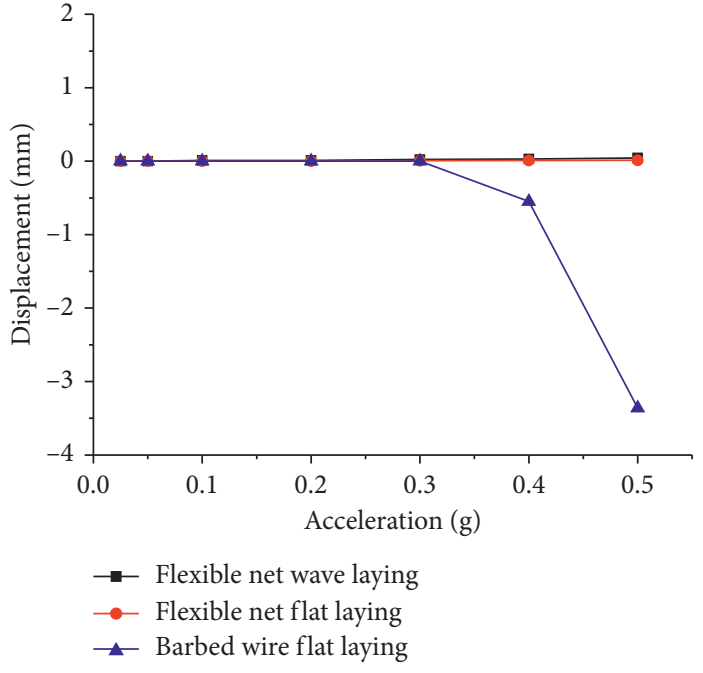

(b)

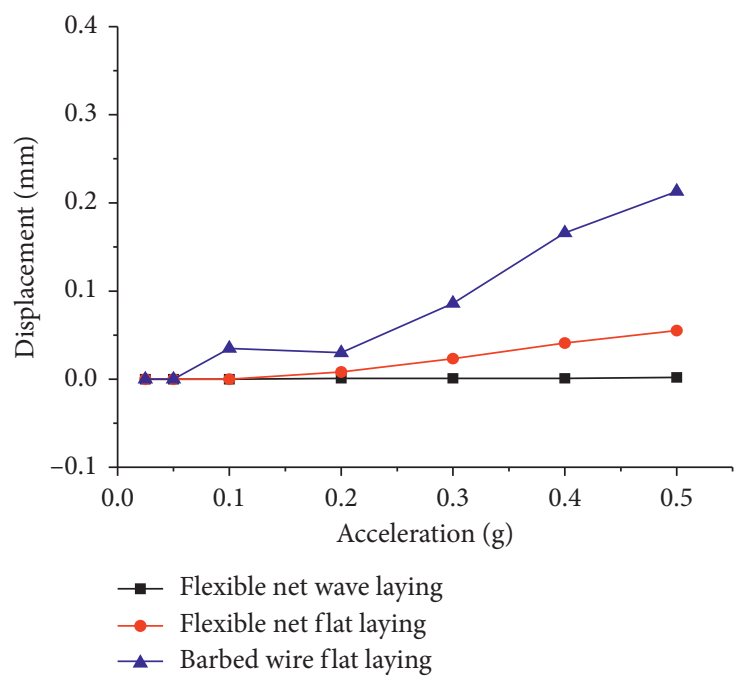

(c)

Figure 15: Substrate layer displacement at a slope of $80^{\circ}$. (a) $H=1.3 \mathrm{~m}$. (b) $H=0.8 \mathrm{~m}$. (c) $H=0.3 \mathrm{~m}$.

(2) Stage 2: internal cracking stage of the substrate layer. The swing amplitude and the slope increased with the continuous increase in seismic action. Crack propagation between the substrate layer and bedrock was limited due to the binding effect of the reinforced net on the substrate layer. Cracks gradually formed in the interior of the substrate. The crack width at the top of the slope was larger than those that occurred in stage 1, as shown in Figure 17(b).

(3) Stage 3: vibration crushing stage of the substrate layer. As shown in Figure 17(c), the crack formed in the previous stage was wide enough that it resulted in the substrate layer block falling off. The slope substrate of the flexible net wavy laying reinforcement resulted in small blocks falling off of the concave side of the wave. Substrate outside of the reinforced net fell off, and the internal substrate of the reinforced net did not fall off in the upper part with the slope of flexible net flat laying reinforcement.
5.2. Instability Mode. Based on the damage phenomenon of the SVC observed in the test, the instability process can be summarized as shown in Figure 18. The slope body swung left and right under the action of a horizontal seismic force, and the crack between the substrate layer and bedrock gradually expanded with the increase in PGA until the cracks extended through the top of the slope. At the same time, internal cracking of the substrate layer began to occur, which causes the interior of the substrate to become loose. Internal cracking of the substrate inner layer increased with the increasing seismic load and eventually caused the SVC to break and fall off.

Compared with the failure modes of the bedding rock slope and restoration slope of the SVC, under the action of a seismic force, the cracks in the top of the slope were broken until the middle crack penetrated through. However, the bedding rock slope slid in the upper part of the slope after the crack penetrated, forming a sliding surface, which ultimately led to sliding failure $[23,24]$. The SVC fell off, which 


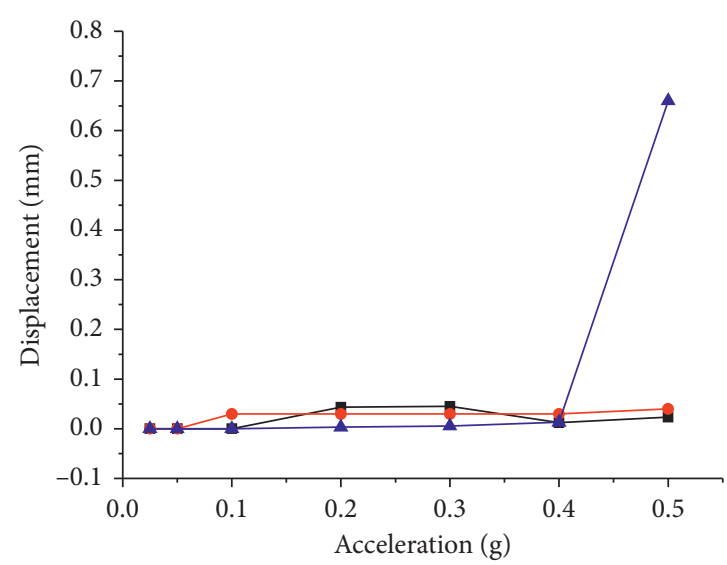

- Slope 4 (flexible net wave laying)

- Slope 5 (flexible net wave laying)

$\_$Slope 6 (flexible net wave laying)

(a)

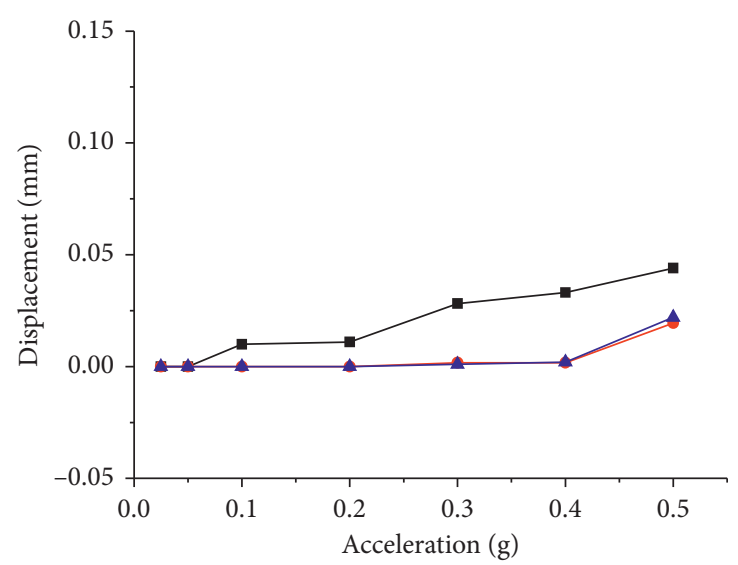

- Slope 4 (flexible net wave laying)

- Slope 5 (flexible net wave laying)

$\_$ـ Slope 6 (flexible net wave laying)

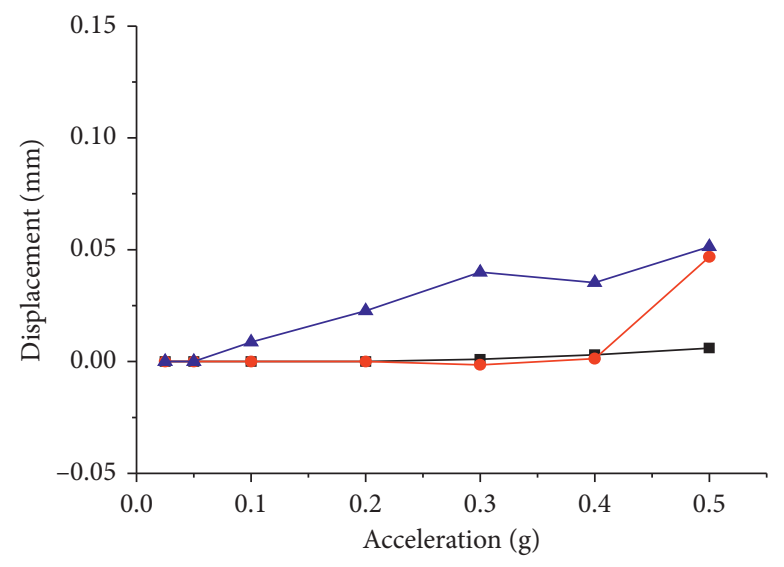

- Slope 4 (flexible net wave laying)

$\rightarrow$ Slope 5 (flexible net wave laying)

$\_$_ Slope 6 (flexible net wave laying)

(c)

Figure 16: Substrate layer displacement at a slope of $60^{\circ}$. (a) $H=1.3 \mathrm{~m}$. (b) $H=0.8 \mathrm{~m}$. (c) $H=0.3 \mathrm{~m}$.

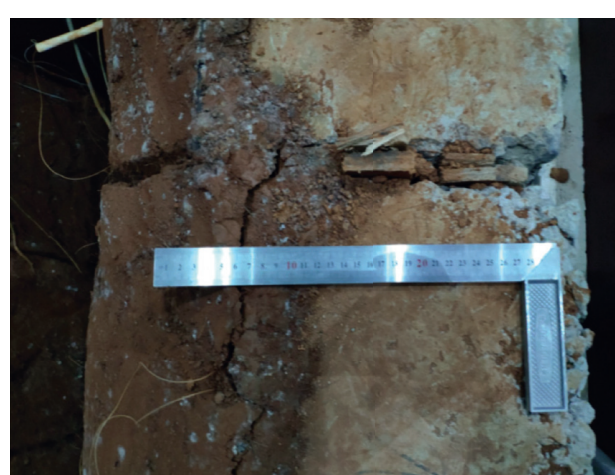

(a)

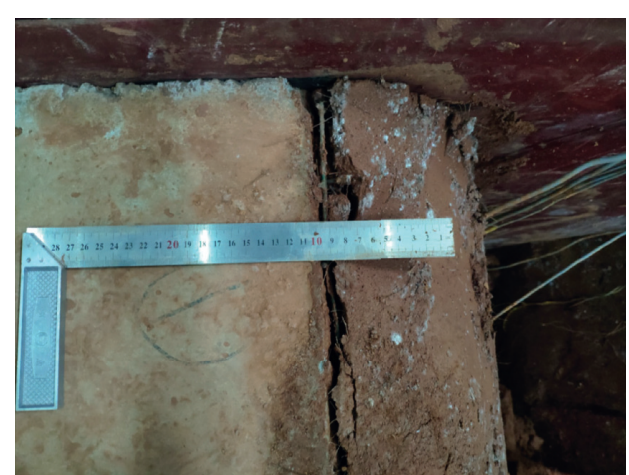

(b)

Figure 17: Continued. 


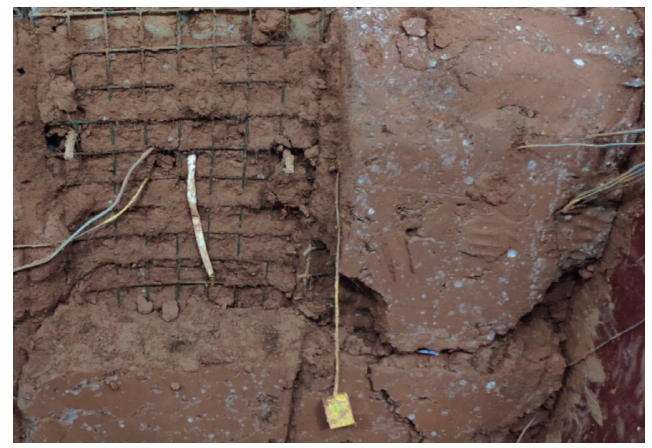

(c)

FIgURE 17: The failure process of SVC. (a) Stage 1: cracking stage between the substrate layer and bedrock. (b) Stage 2: internal cracking stage of the substrate layer. (c) Stage 3: vibration crushing stage of the substrate layer.
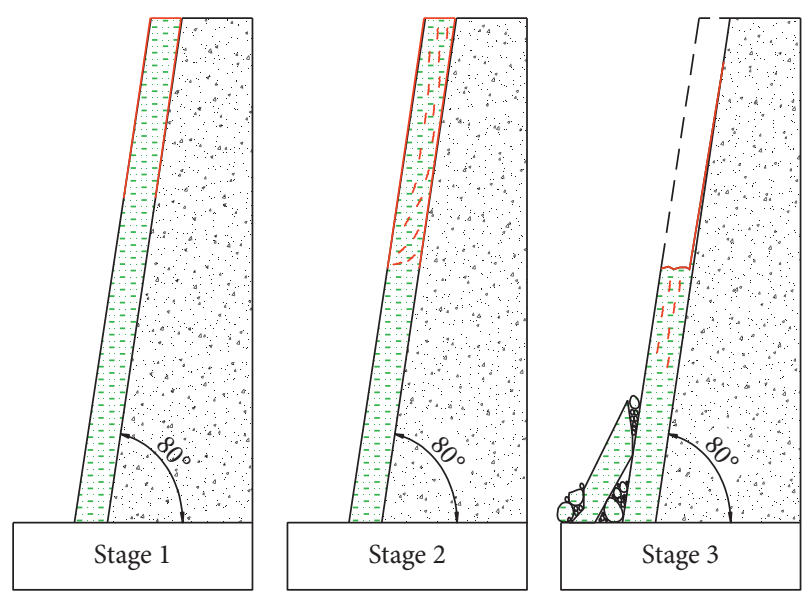

FIgURE 18: Schematic diagram of the instability evolution process of the slope substrate layer.

indicated that the reinforced net had a good restraining effect. However, the deformation of the bedrock was not driven by seismic excitation due to the extremely high strength of the test bedrock mass. In practical engineering, various properties of the bedrock may cause the substrate to fail and result in sliding of the entire slope under the action of a seismic force.

\section{Conclusions}

In this study, the shaking table model test of the seismic performance of SVC was designed and completed. The test scheme and sensor installation of the model were described. By analysis of the displacement and dynamic response of the SVC under seismic action, the following conclusions were drawn.

(1) At different heights of the $80^{\circ}$ slope substrate layer, the displacement of the barbed wire flat laying reinforcement was larger than that of the flexible net flat laying reinforcement. The displacement of the flexible net wave laying reinforcement was the smallest, which indicated that flexible net wavy laying reinforcement was the optimal reinforced net mode.

(2) The SVC displayed good stability under seismic excitation with seismic intensities of V, VI, VII, and VIII. When the seismic intensity reached IX (i.e., the PGA increased from $0.3 \mathrm{~g}$ to $0.5 \mathrm{~g}$ ), the displacement between the substrate layer and bedrock body gradually increased, and the stability of the base substrate layer gradually decreased until it was destroyed.

(3) The failure process of the substrate layer occurred in three stages: cracking between the substrate layer and bedrock, internal cracking of the substrate layer, and vibration crushing. The slope substrate of the flexible net wavy laying reinforcement resulted in small blocks falling off of the concave side of the wave.

\section{Data Availability}

The data used to support the findings of this study are available from the corresponding author upon request.

\section{Conflicts of Interest}

The authors declare that there are no conflicts of interest regarding the publication of this paper.

\section{Acknowledgments}

This study was supported by, the Foundation of Engineering Research Center of Eco-Environment in Three Gorges Reservoir Region of China (grant no. KF2018-01), the National Natural Science Foundation of China (grant no. 41602332), the Youth Scientific and Technological Innovation Team of Southwest Petroleum University (grant no. 2018CXTD02), the National Key R\&D Program of China (grant no. 2017YFC0504901), and the State Key Laboratory for Geomechanics and Deep Underground Engineering, China University of Mining \& Technology (grant no. SKLGDUEK1910). 


\section{References}

[1] Z.-Q. Wang, L.-H. Wu, and T.-T. Liu, "Revegetation of steep rocky slopes: planting climbing vegetation species in artificially drilled holes," Ecological Engineering, vol. 35, no. 7, pp. 1079-1084, 2009.

[2] L. Gao, Z. Miao, Z. Bai, X. Zhou, J. Zhao, and Y. Zhu, "A case study of ecological restoration at the Xiaoyi Bauxite mine, Shanxi Province, China," Ecological Engineering, vol. 11, no. $1-4$, pp. 221-229, 1998.

[3] T. Haneda, "Construction example of earth retaining work example of vegetation construction," Civil Engineering, vol. 35, p. 93, 1980 in Japanese.

[4] A. An, Slope Revegetation Method: Stabilization and Revegetation of Slopes, Morikita Publishing, Tokyo, Japan, 1983.

[5] J. E. Sigsby, S. Tejada, W. Ray, J. M. Lang, and J. W. Duncan, "Volatile organic compound emissions from 46 in-use passenger cars," Environmental Science \& Technology, vol. 21, no. 5, pp. 466-475, 1987.

[6] J. Y. Zhang, D. P. Zhou, and S. C. Li, "Test on slope ecoengineering by spraying a thick layer material," Bulletin of Soil and Water Conservation, vol. 21, no. 4, pp. 47-49, 2001, in Chinese.

[7] Y. Luo, D. Zhou, and J. Zhang, "Experiments on a new material for the ecological protection of rock slopes," Energy Procedia, vol. 16, pp. 272-277, 2012.

[8] W. N. Xu, T. Q. Wang, and J. J. Ye, "Research on application of greening technology for rock slope protection," Water Resources and Hydropower Engineering, vol. 33, no. 7, pp. 35-36, 2002, in Chinese.

[9] Y.S. Yang, W. N. Xu, D. X. Liu, and Z. Y. Xia, "Evaluation and eco-regulation of eco-restoration engineering on slopes of hydropower projects," Nature Environment \& Pollution Technology, vol. 17, no. 1, pp. 131-138, 2018.

[10] C. L. Li, J. P. Xu, G. Wu, and J. W. Zhang, "The application of fine soil aggregate in ecological restoration of abandoned quarry," Environmental Engineering, vol. 29, pp. 278-281, 2011, in Chinese.

[11] M. Zhao, Y. Jia, L. Yuan, J. Qiu, and C. Xie, "Experimental study on the vegetation characteristics of biochar-modified vegetation concrete," Construction and Building Materials, vol. 206, pp. 321-328, 2019.

[12] Y. Yang, J. Yang, T. Zhao, X. Huang, and P. Zhao, "Ecological restoration of highway slope by covering with straw-mat and seeding with grass-legume mixture," Ecological Engineering, vol. 90, pp. 68-76, 2016.

[13] D. Fu, H. Yang, L. Wang et al., "Vegetation and soil nutrient restoration of cut slopes using outside soil spray seeding in the plateau region of southwestern China," Journal of Environmental Management, vol. 228, pp. 47-54, 2018.

[14] Y. Xu and F. Chena, "Effects of concrete content in vegetation concrete matrix on seed germination and seeding establishment of Cynodon dactylon," Procedia Engineering, vol. 28, pp. 105-109, 2012.

[15] S. J. Martel, "Mechanics of landslide initiation as a shear fracture phenomenon," Marine Geology, vol. 203, no. 3-4, pp. 319-339, 2004.

[16] J. J. Roering, K. M. Schmidt, J. D. Stock, W. E. Dietrich, and D. R. Montgomery, "Shallow landsliding, root reinforcement, and the spatial distribution of trees in the Oregon Coast Range," Canadian Geotechnical Journal, vol. 40, no. 2, pp. 237-253, 2003.

[17] L. Zhang, Z. Y. Xia, Z. J. Zhou et al., "Experimental study on tensile properties and reinforcement ability of plant roots,"
Nature Environment and Technology Pollution, vol. 17, no. 3, pp. 729-738, 2018.

[18] A. Kriker, G. Debicki, A. Bali, M. M. Khenfer, and M. Chabannet, "Mechanical properties of date palm fibres and concrete reinforced with date palm fibres in hot-dry climate," Cement and Concrete Composites, vol. 27, no. 5, pp. 554-564, 2005.

[19] N. G. Ozerkan, B. Ahsan, S. Mansour, and S. R. Iyengar, "Mechanical performance and durability of treated palm fiber reinforced mortars," International Journal of Sustainable Built Environment, vol. 2, no. 2, pp. 131-142, 2013.

[20] W. N. Xu, J. J. Ye, M. T. Zhou, and G. X. Kou, "Several problems of vegetation technology for protecting slopes using vegetation-growing concrete," Water Resources and Hydropower Engineering, vol. 35, no. 10, pp. 50-52, 2004, in Chinese.

[21] S. L. Li, W. N. Xu, and L. R. Liu, "Study on eco-restoration of excavated-rockslope: a case study of Qiusuo Zhongchuang center project in Yichang," Water Resources and Hydropower Engineering, vol. 49, no. 4, pp. 130-137, 2018, in Chinese.

[22] E. Guler and O. Selek, "Reduced-scale shaking table tests on geosynthetic-reinforced soil walls with modular facing," Journal of Geotechnical and Geoenvironment Engineering, vol. 140, no. 6, 2014.

[23] J. Y. Dong, G. X. Yang, F. Q. Wu, and S. W. Qi, “The largescale shaking table test study of dynamic response and failure mode of bedding rock slope under earthquake," Rock and Soil Mechanics, vol. 32, no. 10, pp. 2977-2982, 2011, in Chinese.

[24] Y. L. Fan, W. B. Zhang, Z. J. Zhou et al., "Research on dynamic response of rock slopes with discontinuous joints," Journal of Railway Science and Engineering, vol. 14, no. 6, pp. 78-85, 2017, in Chinese. 